\title{
Are There Differences in Zonal Distribution and Tumor Volume of Prostate Cancer in Patients with a Positive Family History?
}

\author{
Wade J. Sexton, Philippe E. Spiess, Louis L. Pisters, Scott Carpenter, Lydia T. Madsen, Robin Zagone, \\ Xuemei Wang, Patricia Troncoso
}

Genitourinary Oncology Program (WJS, PES), H. Lee Moffitt Cancer Center, Tampa, Florida, USA and Departments of Urology (LLP, SC, LTM, RZ), Quantitative Sciences (XW), and Pathology (PT), The University of Texas M. D. Anderson Cancer Center, Houston, Texas, USA

\begin{abstract}
Purpose: To determine if there are any differences in the zonal distribution and tumor volumes of familial and sporadic prostate cancers (PC) in men undergoing radical prostatectomy.

Material and Methods: 839 patients underwent a radical prostatectomy in the absence of prior neoadjuvant therapy between 1987 and 1996. Telephone interviews were conducted to obtain an updated family history. A positive family history was defined as the diagnosis of PC in at least one first degree relative. Prostatectomy specimens were examined to determine the number of tumor foci, zonal origin of the dominant tumor focus, tumor volume of the largest cancer focus, total tumor volume, Gleason score and stage, and the surgical margin status. Results were stratified according to family history and ethnicity.

Results: We successfully contacted 437 patients (52\%). Prostatectomy specimens from 55 patients were excluded from review due to a history of prior transurethral resection of the prostate

$(n=26)$ or uncertain pathological stage $(n=29)$. Of the remaining 382 patients, $76(20 \%)$ reported having a first-degree relative with PC. Statistical analysis revealed no significant differences in the pathologic variables between the two groups of patients with or without a family history of PC.

Conclusions: Familial and sporadic PC share similar characteristics. No histopathological differences account for the increased positive predictive value of PC screening tests among patients with a family history of PC.
\end{abstract}

Key words: prostatic neoplasms; tumor burden; family characteristics; tumor volume; pathology

Int Braz, J Urol. 2010; 36: 571-82

\section{INTRODUCTION}

The reported rate of positive family history among men with prostate cancer (PC) ranges from $13 \%$ to $26 \%$ and approaches $40 \%$ for men diagnosed with the disease before age 55 (1-3). Detection of cancer in multiple first-degree or second-degree relatives coupled with early age at cancer diagnosis substantially increases a man's relative risk and absolute risk of developing PC (4).

Whereas a number of earlier studies evaluated family history and radical prostatectomy (RP) pathology to determine the significance of a positive family history as a risk factor for PC, they were directed largely at the number of tumors, the pathologic stage, and outcome measures including biochemical disease- 
free survival (DFS) and overall survival (5-9). Very little information is available on the zonal distribution of cancers in patients with a positive family history. Furthermore, there are no pathologic data that explain the increased positive-predictive value reported for abnormal digital rectal examination (DRE) and prostate-specific antigen (PSA) tests in high-risk patients, such as those with a positive family history $(10,11)$. We as well do not currently know if there exist differences in terms of tumor volumes between patients with and without a family history of PC?

We hypothesized that RP specimens from patients with a family history of $\mathrm{PC}$ might reveal different tumor characteristics compared with specimens from patients with sporadic PC and that the different characteristics could account for the higher diagnostic yield of prostate biopsies performed in patients with risk factors for disease. To address this hypothesis, we specifically examined the zonal distribution of cancer foci, tumor location, and tumor volume differences of our surgically managed patients with and without a family history of PC. We also analyzed corresponding clinicopathologic data, such as age, preoperative PSA levels, pathologic stage, Gleason score, and surgical margin status in patient groups stratified by family history.

\section{MATERIALS AND METHODS}

A research protocol was designed and approved by our Institutional Review Board prior to the initiation of this study. From January 1987 to December 1996, 839 patients underwent RP at The University of Texas M. D. Anderson Cancer Center, with no prior neoadjuvant therapy. The patients were followed for at least 6 years from the time of RP. Family history data were obtained by telephone interview to update the patient's file and to capture additional family members affected with PC since the index patient's surgical procedure. The patients and immediate family members who were successfully contacted were included in the study. Positive family history was defined as having at least 1 firstdegree relative (e.g., brother, son, father) who had a diagnosis of PC. Only a few patients with possible hereditary prostate cancer (HPC) were included in the analysis. HPC is believed to be transmitted in an autosomal dominant fashion, and it is postulated that HPC accounts for $5 \%$ to $10 \%$ of all cases of PC (and possibly $30 \%$ to $45 \%$ of early onset cancers). To be classified as having HPC, patients had to fulfill one of the following clinical criteria: PC occurring in 3 successive generations (maternal or paternal side), 3 cases of PC diagnosed within a nuclear family, or 2 men within a single family diagnosed with $\mathrm{PC}$ before age $55(4,12)$.

The prostatectomy specimens were evaluated as previously reported $(13,14)$. Each tumor focus was outlined on the histologic sections, and the total number of tumor foci as well as the zonal origin of each tumor focus were recorded. Zones were categorized as peripheral zone (PZ), transition zone (TZ), or multiple zones (MZ). An area of carcinoma was considered a different focus if it was separated by a low-power field diameter $(4.5 \mathrm{~mm})$ from the nearest adjacent focus, as reported previously (15). Tumor location was recorded according to standardized guidelines (Figure-1). Each tumor focus was graded according to the Gleason grading system (16). The Gleason score assigned to the specimen was that of the tumor focus with the highest Gleason score. The volume of each tumor focus was calculated according to the three-dimensional volume estimation method (17). The 2002 American Joint Committee on Cancer tumor-node-metastasis staging system was used to define organ-confined cancers (T2), established extraprostatic extension (T3a), and cancer involvement of the seminal vesicles (T3b). Patients with positive margins without extraprostatic extension were categorized as having T2 tumors regardless of margin status.

Patients' demographic and clinical characteristics were summarized by family history status. Fisher's exact test was performed to assess the association between categorical variables. The Wilcoxon rank sum test was performed to assess the difference in continuous variables between patients with and those without a family history of PC. In order to assess the predictive effect of family history and ethnicity simultaneously, a multinomial logistic regression model was fit for the outcome variable of "site of dominant tumor focus", which can take the values of "PZ", "TZ", or "MZ". The fitted multinomial logistic regression model can be written as follows: 


\section{TUMOR LOCATION DESCRIPTION}

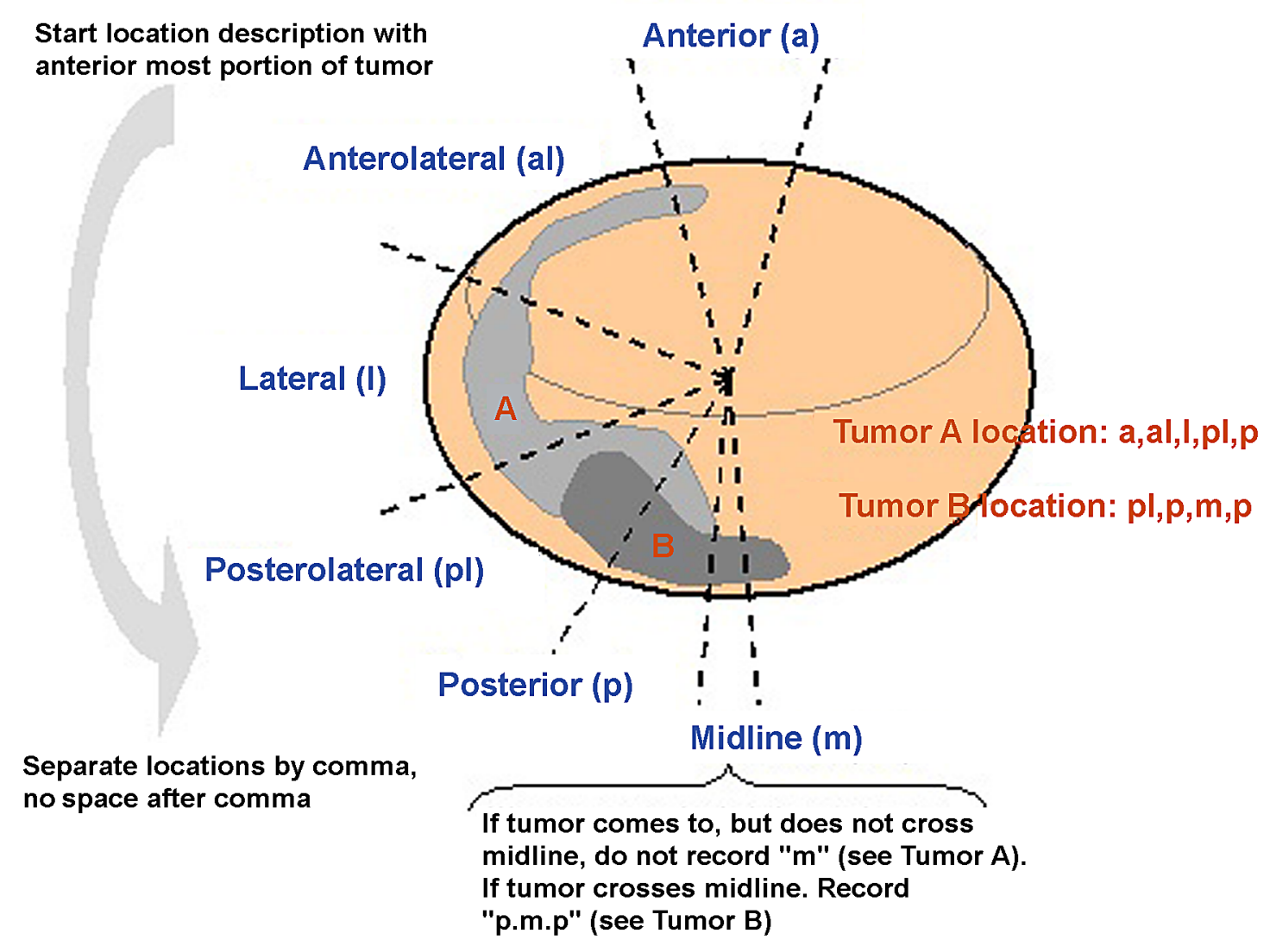

Figure 1 - Guidelines to record tumor location description.

$$
\begin{aligned}
& \operatorname{pr}\left(\gamma_{\mathrm{l}}=1 \mid \mathrm{x}_{\mathrm{l}}\right)=\frac{1}{1+\sum_{\mathrm{j}=2}^{\mathrm{j}} \exp \left(\mathrm{x}_{\mathrm{l}} \beta_{\mathrm{j}}\right)} \text { for } \mathrm{m}=1 \\
& \operatorname{pr}\left(\gamma_{\mathrm{l}}=\mathrm{m} \mid \mathrm{x}_{\mathrm{l}}\right)=\frac{{ }_{\exp }\left(\mathrm{x}_{\mathrm{l}} \beta_{\mathrm{m}}\right)}{1+\Sigma_{\mathrm{j}=2}^{\mathrm{j}} \exp \left(\mathrm{x}_{\mathrm{l}} \beta_{\mathrm{j}}\right)} \text { for } \mathrm{m}>1
\end{aligned}
$$

where $y_{i}$ is the response variable for subject $i$, and can take values of $1,2, \ldots, \mathrm{m}$. In our case, the site of dominant tumor focus could be "P", "T" or "M"; therefore, $m=3$. $X_{\mathrm{i}}$ is vector of covariates for subject $\mathrm{i}$ (here, are family history and ethnicity) and $\beta_{\mathrm{j}}$ is the vector of coefficient, with $\mathrm{j}$ ranges from 2 to J. Note: $\mathrm{J}=\mathrm{m}$. All statistical analyses were carried out in SAS or Splus software program.

\section{RESULTS}

\section{Patient Characteristics}

We successfully contacted 437 (52\%) patients. Specimens from 55 patients were excluded from review due to the patient's history of prior 


\section{Differences in Prostate Cancer Pathology Based on Family History}

Table 1 - Demographic and clinical characteristics.

\begin{tabular}{|c|c|c|c|}
\hline Variable & $\begin{array}{c}\text { Negative FHx } \\
\quad(\mathrm{N}=306)\end{array}$ & $\begin{array}{l}\text { Positive FHx } \\
(\mathrm{N}=76)\end{array}$ & p Value \\
\hline Age & $63.2(42.3-74.7)$ & $62.8(46.7-72.2)$ & 0.43 \\
\hline$\%>=60$ years & $207(67.6 \%)$ & $49(64.5 \%)$ & 0.70 \\
\hline Total Tumor volume & $1.64(0.02-17.44)$ & $1.72(0.04-9.56)$ & 0.27 \\
\hline Tumor volume of largest cancer focus & $1.20(0.02-14.40)$ & $1.36(0.04-7.68)$ & 0.44 \\
\hline Prostate Weight (g) & $40(10-141)$ & $40(18-95)$ & 0.90 \\
\hline Total tumor volume/ Prostate Weight & $0.038(0.00046-0.31)$ & $0.044(0.0005-0.25)$ & 0.27 \\
\hline Ethnicity & & & 0.61 \\
\hline Caucasian & $266(86.9 \%)$ & $70(92.1 \%)$ & \\
\hline African American & $23(7.5 \%)$ & $4(5.3 \%)$ & \\
\hline Hispanic & $15(4.9 \%)$ & $2(2.6 \%)$ & \\
\hline Other & $2(0.7 \%)$ & $0(0.0 \%)$ & \\
\hline Diagnostic PSA & $7.5(0.7-55.0)$ & $7.6(1.3-30.1)$ & 0.50 \\
\hline Pathologic Gleason Score & & & 0.13 \\
\hline 5,6 & $31(10.1 \%)$ & $14(18.4 \%)$ & \\
\hline 7 & $190(62.1 \%)$ & $42(55.3 \%)$ & \\
\hline 8,9 & $85(27.8 \%)$ & $20(26.3 \%)$ & \\
\hline Pathologic Stage & & & 0.44 \\
\hline $\mathrm{T} 2$ & $209(68.3 \%)$ & $46(60.5 \%)$ & \\
\hline T3a & $74(24.2 \%)$ & $23(30.3 \%)$ & \\
\hline $\mathrm{T} 3 \mathrm{~b}$ & $23(7.5 \%)$ & $7(9.2 \%)$ & \\
\hline Surgical Margins & & & 0.52 \\
\hline Negative & $231(75.5 \%)$ & $54(71.1 \%)$ & \\
\hline Positive & $75(24.5 \%)$ & $22(28.9 \%)$ & \\
\hline
\end{tabular}

$T 2=$ organ confined; T3a = established extracapsular tumor; T3b = seminal vesicle involvement by tumor; FHx $=$ family history.

transurethral prostatectomy $(\mathrm{n}=26)$, uncertain or missing pathologic data $(n=29)$, leaving 382 patients with complete clinical and pathologic data. Seventeen patients $(4 \%)$ were believed to have HPC on the basis 
Table 2 - Characterization of affected family members in familial prostate caner cases (includes possible hereditary cancers).

Affected Relatives in Index Patients with 1st Degree Family History ( $\mathrm{N}=76)$

One Relative $(\mathrm{N}=59)$

Father

Brother

Son

Two Relatives $(\mathrm{N}=15)$

Father, Brother

Father, Grandfather

Brother, Brother

Brother, Grandfather

Four Relatives $(\mathrm{N}=2)$

Brothers (x4)

Categories of Possible Hereditary Prostate Cancer $(n=17)$

At least three men within same nuclear family

Three successive generations

Age $<55$ in index patient and at least 1 relative
Number of Affected Relatives

33

25

1

5

5

4

1

2

Number of Cases

11

5

1 of the aforementioned clinical criteria. Table-1 lists clinical information and demographics of the patients with and without a family history of PC. There was no difference in any of the clinical or pathologic features including total tumor volume and tumor volume of the largest tumor focus among patients with and without a family history of PC. Table- 2 characterizes the affected family members in familial prostate cancer and hereditary prostate cancer cases.

\section{Association between Family History, Ethnicity, and Pathologic Features}

The association between family history of PC and pathologic stage was evaluated in Caucasian and other ethnicities (Table-3). No significant association was detected in either Caucasian $(p=0.46)$ or African American patients $(\mathrm{p}=0.18)$. To further clarify the potential association between location of the largest cancer foci and ethnicity, we assessed the location of cancer foci by familial history of prostate cancer (Table-4). We were unable to show an association between the location of the largest cancer focus and familial history of prostate cancer, with substratification of the volume of the largest cancer focus $(<0.5$ cc, 0.5 to $1.5 \mathrm{cc}$, and $>1.5 \mathrm{cc}$ ). Similarly, we attempted to determine if there was an association between the location of the second largest cancer focus and family history of prostate cancer (Table-4), with no statistically signification association noted. Table- 5 shows the location of the dominant tumor focus according to the patient's reported family history and race. Positive family history of PC did not significantly impact ( $p$ $=0.73$ ) the dominant tumor focus. On multinomial logistic regression analysis, the lack of association between ethnicity and site of dominant tumor focus was preserved (Tables 6 and 7). Furthermore, we compared the number of tumor foci based on either family history or ethnicity (Table-8). The mean and median number of tumor foci did not show a significant difference based on family history of PC or ethnicity. 
Table 3 - Pathologic T stage stratified by family history and ethnicity.

\begin{tabular}{lcccc}
\hline Ethnicity & Pathologic T-stage & Negative Family History & Positive Family History & p Value \\
\hline Caucasian & & $180(67.7 \%)$ & $42(60.0 \%)$ & 0.46 \\
& T2 & $65(24.4 \%)$ & $22(31.4 \%)$ & \\
African American & T3a & $21(7.9 \%)$ & $6(8.6 \%)$ & \\
& & & $3(75.0 \%)$ & \\
& T2 & $16(69.6 \%)$ & 0.18 & \\
& T3a & $6(26.1 \%)$ & $1(25.0 \%)$ & \\
\hline
\end{tabular}

$T 2=$ organ confined; $T 3 a=$ established extracapsular tumor; $T 3 b=$ seminal vesicle involvement by tumor.

\section{COMMENTS}

Most physicians recommend early screening for PC in populations at high risk for the disease. High-risk populations include men with a positive family history of PC and African American men (18). The risk is even greater for men with multiple risk factors or for those whose affected relatives were diagnosed with cancer at younger ages (less than 5560 years of age) (4).

Several studies have sought the patterns of RP pathology that could be unique to patients with a family history of PC. Studies have focused on the number of tumors, Gleason score, pathologic stage, and biochemical DFS and cancer-specific survival rates (1,5-9). However, there is very little information about the zonal distribution of prostate cancer in patients with a positive family history. Similarly, tumor volume has been shown to be an independent predictor of biochemical failure yet there is little to no information on the association between either tumor volume (either total or of the dominant focus of prostate cancer) among patients with or without a family history of PC $(13,19)$.

Prostate cancer is characterized as a multifocal disease, and the majority of cancers are located in the PZ area most commonly targeted and sampled during prostate biopsies. Catalona et al. (10) reported that there is a higher positive predictive value of $\mathrm{PC}$ screening tests (PSA and DRE) for detecting PC in patients with established risk factors such as family history and African American ethnicity while controlling for both age and PSA. It seems intuitive that prostatectomy specimens from patients with risk factors for disease might contain more dominant tumor foci located peripherally in targeted biopsy zones, a greater number of tumor foci, or a greater percentage of cancer per prostate specimen to account for the significantly higher yield of prostate biopsies. However, our pathology results do not support the hypothesis that differences in the zonal origin of the dominant tumor focus or differences in the number of tumor foci could account for higher cancer detection rates in patients with PC risk factors. There were no significant differences in the mean number of tumor foci based on family history or on ethnicity. Most dominant tumor foci were located peripherally and family history did not alter the distribution of the dominant tumor foci between the PZ, TZ, or MZ. Contrary to family history status, when the locations of the dominant tumor foci were stratified according to ethnicity, non-Caucasians were demonstrated to have more dominant tumor foci originating within the transition zone compared to Caucasian patients.

In an attempt to clarify if the location of the largest and second largest tumor foci were different based on family history of PC, we were unable to identify an association between site of these predominant tumor foci and familial history of PC. This may have had important clinical implications in terms of the 
Table 4 - The association between location of tumor foci and family history within patients having largest tumor and second largest tumor less than $0.5 \mathrm{cc}$, between $0.5 \mathrm{cc}$ and $1.5 \mathrm{cc}$, and greater than $1.5 \mathrm{cc}$.

\begin{tabular}{|c|c|c|c|}
\hline \multirow{2}{*}{$\begin{array}{l}\text { Location } \\
\text { Largest Tumor }\end{array}$} & \multicolumn{2}{|c|}{ Family History } & \multirow[b]{2}{*}{ p Value } \\
\hline & Negative & Positive & \\
\hline \multicolumn{4}{|l|}{$<0.5 \mathrm{cc}$} \\
\hline L,PL,P & $10(16.7)$ & $1(8.3)$ & \multirow{5}{*}{0.78} \\
\hline PL & $23(38.3)$ & $5(41.7)$ & \\
\hline PL,P & $16(26.7)$ & $5(41.7)$ & \\
\hline $\mathrm{L}, \mathrm{PL}$ & $10(16.7)$ & $1(8.3)$ & \\
\hline $\mathrm{L}$ & $1(1.7)$ & $0(0)$ & \\
\hline \multicolumn{4}{|l|}{$0.5-1.5 \mathrm{cc}}$. \\
\hline L,PL,P & $42(52.5)$ & $15(50)$ & \multirow{6}{*}{0.71} \\
\hline PL & $4(5)$ & $2(6.7)$ & \\
\hline PL,P & $13(16.2)$ & $4(13.3)$ & \\
\hline L,PL & $13(16.2)$ & $4(13.3)$ & \\
\hline AL,L,PL,P & $8(10)$ & $4(13.3)$ & \\
\hline $\mathrm{L}$ & $0(0)$ & $1(3.3)$ & \\
\hline \multicolumn{4}{|l|}{$>1.5 \mathrm{cc}$} \\
\hline $\mathrm{L}, \mathrm{PL}, \mathrm{P}$ & $21(48.8)$ & $4(50)$ & \multirow{4}{*}{1.00} \\
\hline PL,P & $4(9.3)$ & $1(12,5)$ & \\
\hline $\mathrm{L}, \mathrm{PL}$ & $1(2.3)$ & $0(0)$ & \\
\hline AL,L,PL,P & $17(39.5)$ & $3(37.5)$ & \\
\hline \multicolumn{4}{|c|}{ Second largest tumor } \\
\hline \multicolumn{4}{|l|}{$<0.5 \mathrm{cc}$} \\
\hline $\mathrm{L}, \mathrm{PL}, \mathrm{P}$ & $56(38.6)$ & $17(41.5)$ & \multirow{6}{*}{0.45} \\
\hline PL & $21(14.5)$ & $7(17.1)$ & \\
\hline PL,P & 27 (18.6) & $8(19.5)$ & \\
\hline L,PL & $21(14.5)$ & $4(9.8)$ & \\
\hline AL,L,PL,P & $20(13.8)$ & $4(9.8)$ & \\
\hline L & $0(0)$ & $1(2.4)$ & \\
\hline \multicolumn{4}{|l|}{$0.5-1.5 \mathrm{cc}}$. \\
\hline $\mathrm{L}, \mathrm{PL}, \mathrm{P}$ & $21(48.8)$ & $4(50)$ & \multirow{4}{*}{0.4} \\
\hline PL,P & $4(9.3)$ & $1(12,5)$ & \\
\hline $\mathrm{L}, \mathrm{PL}$ & $1(2.3)$ & $0(0)$ & \\
\hline AL,L,PL,P & $17(39.5)$ & $3(37.5)$ & \\
\hline \multicolumn{4}{|l|}{$>1.5 \mathrm{cc}$} \\
\hline L,PL,P & 2 & 0 & 0.4 \\
\hline
\end{tabular}

$A=$ Anterior; AL: anterolateral; $L=$ lateral; $P$ : posterior; $P L=$ posterolateral. $P$ values determined using Fisher's exact test. 
Table 5 - Site of dominant tumor focus stratified by family history and ethnicity.

\begin{tabular}{lcccc}
\hline & PZ & Dominant Tumor Focus & p Value \\
\hline Family History & & TZ & MZ & 0.73 \\
$\quad$ Negative & & & \\
$\quad \begin{array}{l}\text { Positive } \\
\text { Ethnicity }\end{array}$ & $242(79.1 \%)$ & $59(19.3 \%)$ & $5(1.6 \%)$ & \\
$\quad$ Caucasian & $64(84.2 \%)$ & $11(14.5 \%)$ & $1(1.3 \%)$ & 0.06 \\
All Others & $275(81.8 \%)$ & $56(16.7 \%)$ & $5(1.5 \%)$ & \\
& $31(67.4 \%)$ & $14(30.4 \%)$ & $1(2.2 \%)$ & \\
$\quad$ African American & $17(63.0 \%)$ & $9(33.3 \%)$ & $1(3.7 \%)$ & 0.04 \\
All Others & $289(81.4 \%)$ & $61(17.2 \%)$ & $5(1.4 \%)$ & \\
\hline
\end{tabular}

$P Z=$ peripheral zone; $T Z=$ transition zone; $M Z=$ multiple zones.

transrectal ultrasound guided prostatic biopsy schemes to apply to patients based on familial history of PC. However, due to the lack of an association between the site of the largest and second largest tumor focus and family history of PC, an extensive biopsy scheme consisting of 10 to 12 biopsy cores should be obtained in all patients in whom prostatic biopsies are clinically indicated.

Racial variation in the location of dominant tumor foci has been reported previously. Pettaway and colleagues found that $35 \%$ of all tumor foci in African American men were of TZ origin compared with $21 \%$ of the tumor foci in a group of Caucasian patients matched according to pathologic stage. In this same study, the median number of tumor foci and the overall prostatic tumor volumes (stratified by pathologic stage and zone of origin of the cancers) were not statistically different (20). Pettaway et al. hypothesized that the TZ epithelium in African American patients might be more susceptible to malignant transformation compared with the TZ epithelium of Caucasian men (20).

A smaller study failed to reveal significant differences in tumor multifocality and the zonal distribution of tumor foci in patients with a positive family history. Bastacky et al. (21) examined the morphologic characteristics of 81 radical prostatectomy specimens from selected small groups of patients with sporadic PC, familial PC, and HPC. In this study, patients with sporadic $\mathrm{PC}$ had a mean 7.3 tumor foci per

Table 6 - Fitted multinomial logistic regression model for zone distribution.

\begin{tabular}{|c|c|c|c|c|c|c|}
\hline Parameter & Zone & Estimate & $\begin{array}{c}\text { Standard } \\
\text { Error }\end{array}$ & Probability $>$ Chi Sq & Point Estimate & $95 \% \mathrm{CI}$ \\
\hline Intercept & $\mathrm{TZ}$ & -1.4944 & 0.1536 & $<0.0001$ & & \\
\hline Intercept & $\mathrm{MZ}$ & -4.0096 & 0.4906 & $<0.0001$ & & \\
\hline FH (pos vs. neg) & $\mathrm{TZ}$ & -0.3282 & 0.3590 & 0.36 & 0.72 & $0.356-1456$ \\
\hline FH (pos. vs. neg) & $\mathrm{MZ}$ & -0.2464 & 1.1066 & 0.82 & 0.78 & $0.089-6.838$ \\
\hline Black vs. Others & $\mathrm{TZ}$ & 0.9050 & 0.4364 & 0.04 & 2.47 & $1.051-5.815$ \\
\hline Black vs. Others & $\mathrm{MZ}$ & 1.2126 & 1.1246 & 0.28 & 3.36 & $0.371-30.468$ \\
\hline
\end{tabular}

$F H=$ family history; $M Z=$ multiple zones; $T Z=$ transition zone. 
Differences in Prostate Cancer Pathology Based on Family History

Table 7 - Fitted multinomial logistic regression model for zone distribution.

\begin{tabular}{lcccccc}
\hline Parameter & Zone & Estimate & $\begin{array}{c}\text { Standard } \\
\text { Error }\end{array}$ & Probability $>$ Chi Sq & Point Estimate & 95\% CI \\
\hline Intercept & $\mathrm{TZ}$ & -1.5327 & 0.1598 & $<.0001$ & & \\
Intercept & $\mathrm{MZ}$ & -3.9581 & 0.4924 & $<.0001$ & & \\
FH (pos vs. neg) & $\mathrm{TZ}$ & -0.3054 & 0.3595 & 0.40 & 0.737 & $0.364-1.491$ \\
FH (pos. vs. neg) & $\mathrm{MZ}$ & -0.2503 & 1.1069 & 0.82 & 0.779 & $0.089-6.815$ \\
Non-White vs. White & $\mathrm{TZ}$ & 0.7756 & 0.3548 & 0.03 & 2.172 & $1.083-4.354$ \\
Non-White vs. White & $\mathrm{MZ}$ & 0.5559 & 1.1140 & 0.62 & 1.743 & $0.196-15.477$ \\
\hline
\end{tabular}

$F H=$ family history; $M Z=$ multiple zones; $T Z=$ transition $z o n e$.

gland compared with a mean 5.2 tumor foci per gland in the familial PC group. On the contrary, patients with familial PC had a larger volume of cancer per gland compared with the sporadic $\mathrm{PC}$ group $\left(3.3 \mathrm{~cm}^{3}\right.$ vs. $2.4 \mathrm{~cm}^{3}$ ). However, these results failed to reach statistical significance likely due to the small number of patients in each of the three groups.

Although patients with a positive family history of PC are at higher risk of developing the disease, most studies suggest that these patients have either equivalent (12) or more favorable disease characteristics, such as lower Gleason scores $(1,7,21)$ or less extracapsular tumor extension (9). Furthermore, there is no convincing evidence that survival is better or worse for patients with a positive family history of PC undergoing RP $(5,8,9)$ or primary radiation therapy (22) compared to patients with sporadic PC.
Surprisingly, only one group reported differences in biochemical DFS following RP or primary radiation therapy favoring patients with sporadic PC. Even in this study, there were no clinical or pathologic differences to account for the inferior biochemical outcome for patients with a positive family history (6). Regardless of the disease outcome, no study to date (including our report) has been able to demonstrate different pathologic or morphologic characteristics in prostate specimens from patients with a positive family history compared with patients without a family history of PC that would account for an approximately $10 \%$ increase in the positive predictive value of current diagnostic screening tests (PSA and DRE) on PC detection $(10,11,23)$. Consistent with previous reports, our study revealed no significant differences between patients with a family history of

Table 8 - Mean number of tumor foci stratified by family history and ethnicity.

\begin{tabular}{llcc}
\hline & \multicolumn{2}{c}{ Number of Tumor Foci } \\
Mean & Median (range) & p Value \\
\hline $\begin{array}{l}\text { Family History } \\
\quad \text { Negative }\end{array}$ & 3.31 & $3(1-10)$ & 0.55 \\
$\quad \begin{array}{l}\text { Positive } \\
\text { Ethnicity }\end{array}$ & 3.18 & $3(1-8)$ & \\
$\quad$ Caucasian & 3.27 & $3(1-10)$ & 0.32 \\
$\quad$ All others & 3.41 & $3(1-7)$ & 0.29 \\
$\quad$ African American & 3.52 & $3(1-7)$ & \\
$\quad$ All others & 3.27 & $3(1-10)$ & \\
\hline
\end{tabular}


PC compared to patients without a family history of PC in terms of age, preoperative PSA, Gleason score, pathologic stage, and surgical margin status. We did not examine disease-specific or biochemical DFS. Based on the pathologic results from both patient groups, it is unlikely that there would be meaningful differences in these outcome measures.

Several potential biases with this study deserve mention. Although our data were stratified according to ethnicity, few non-Caucasian patients were included in the overall analysis. Patients included in this study all underwent RP. Thus, our population may not represent the full spectrum of familial and sporadic PC. Other potential risk factors, such as obesity and diet, may significantly affect cancer initiation, promotion, and progression, and were not accounted for in this analysis $(24,25)$. Regarding family history, we did not confirm reported positive family histories with pathology reports of affected relatives. Neither were we able to accurately determine the exact age of most of the affected family members at the time of their own diagnosis. However, recognizing some of these potential biases at study onset, we did not rely on medical record family history data for study inclusion, thus excluding nearly half of the patients undergoing RP during the study period. We attempted to clarify and update family history data via telephone interviews with the patients or with their immediate family members. However, an accurate assessment of the significance of family history related to the development of PC will be limited as long as the definition of a positive family history is based on clinical criteria and not on molecular fingerprints or biomarkers that might establish a true familial link to PC among affected individuals.

\section{CONCLUSIONS}

Patients with familial and sporadic PC have pathologically and morphologically similar tumors. In our study group, there were no clinically significant differences in the zonal origin and location of the dominant tumor foci, tumor volume, or number of tumor foci to account for the reported increased positive predictive value of diagnostic screening tests in patients with a family history of PC.

\section{ACKNOWLEDGEMENTS}

We thank Cindy Soto BS, HT (ASCP) and Ina Prokhorova, MD, HT, HTL (ASCP) for expert technical assistance with the pathologic specimens, Brooke Reynolds for assistance in preparation of the manuscript, and $\mathrm{Kim} \mathrm{Vu}$ for assistance in preparation of the illustrations.

\section{CONFLICT OF INTEREST}

None declared.

\section{REFERENCES}

1. Keetch DW, Humphrey PA, Smith DS, Stahl D, Catalona WJ: Clinical and pathological features of hereditary prostate cancer. J Urol. 1996; 155: 1841-3.

2. Bratt $\mathrm{O}$, Kristoffersson U, Lundgren R, Olsson H: Familial and hereditary prostate cancer in southern Sweden. A population-based case-control study. Eur J Cancer. 1999; 35: 272-7.

3. Carter BS, Beaty TH, Steinberg GD, Childs B, Walsh PC: Mendelian inheritance of familial prostate cancer. Proc Natl Acad Sci U S A. 1992; 89: 3367-71.

4. Bratt O: Hereditary prostate cancer: clinical aspects. J Urol. 2002; 168: 906-13.

5. Azzouzi AR, Valeri A, Cormier L, Fournier G, Mangin P, Cussenot O: Familial prostate cancer cases before and after radical prostatectomy do not show any aggressiveness compared with sporadic cases. Urology. 2003; 61: 1193-7.

6. Kupelian PA, Kupelian VA, Witte JS, Macklis R, Klein EA: Family history of prostate cancer in patients with localized prostate cancer: an independent predictor of treatment outcome. J Clin Oncol. 1997; 15: 147880 .

7. Kotsis SV, Spencer SL, Peyser PA, Montie JE, Cooney KA: Early onset prostate cancer: predictors of clinical grade. J Urol. 2002; 167: 1659-63.

8. Grönberg H, Damber L, Tavelin B, Damber JE: No difference in survival between sporadic, familial and hereditary prostate cancer. Br J Urol. 1998; 82: 564-7.

9. Norrish AE, McRae CU, Cohen RJ, Jackson RT: A population-based study of clinical and pathological prognostic characteristics of men with familial and sporadic prostate cancer. BJU Int. 1999; 84: 311-5. 
10. Catalona WJ, Antenor JA, Roehl KA, Moul JW. Screening for prostate cancer in high risk populations. J Urol. 2002; 168: 1980-3; discussion 1983-4.

11. Aprikian AG, Bazinet M, Plante M, MeshrefA, Trudel C, Aronson S, et al.: Family history and the risk of prostatic carcinoma in a high risk group of urological patients. J Urol. 1995; 154: 404-6.

12. Carter BS, Bova GS, Beaty TH, Steinberg GD, Childs $\mathrm{B}$, Isaacs WB, et al.: Hereditary prostate cancer: epidemiologic and clinical features. J Urol. 1993; 150: 797-802.

13. Babaian RJ, Troncoso P, Steelhammer LC, LloretaTrull J, Ramirez EI: Tumor volume and prostate specific antigen: implications for early detection and defining a window of curability. J Urol. 1995; 154: 1808-12.

14. Sanchez-Ortiz RF, Troncoso P, Babaian RJ, Lloreta J, Johnston DA, Pettaway CA: African-American men with nonpalpable prostate cancer exhibit greater tumor volume than matched white men. Cancer. 2006; 107: $75-82$.

15. Troncoso P, Babaian RJ, Ro JY, Grignon DJ, von Eschenbach AC, Ayala AG: Prostatic intraepithelial neoplasia and invasive prostatic adenocarcinoma in cystoprostatectomy specimens. Urology. 1989; 34(6 Suppl): 52-6.

16. Gleason D: Histologic grading and clinical staging of prostate carcinoma. In: Tannenbaum M (ed.), Urologic Pathology. The Prostate. Philadelphia, Lea \& Febiger. 1977: pp. 171-97.

17. Chen ME, Johnston D, Reyes AO, Soto CP, Babaian RJ, Troncoso P: A streamlined three-dimensional volume estimation method accurately classifies prostate tumors by volume. Am J Surg Pathol. 2003; 27: 1291-301.
18. Crawford ED: Epidemiology of prostate cancer. Urology. 2003; 62(6 Suppl1): 3-12.

19. Nelson BA, Shappell SB, Chang SS, Wells N, Farnham $\mathrm{SB}$, Smith JA Jr, et al.: Tumour volume is an independent predictor of prostate-specific antigen recurrence in patients undergoing radical prostatectomy for clinically localized prostate cancer. BJU Int. 2006; 97: 1169-72.

20. Pettaway CA, Troncoso P, Ramirez EI, Johnston DA, Steelhammer L, Babaian RJ: Prostate specific antigen and pathological features of prostate cancer in black and white patients: a comparative study based on radical prostatectomy specimens. J Urol. 1998; 160: 437-42.

21. Bastacky SI, Wojno KJ, Walsh PC, Carmichael MJ, Epstein JI: Pathological features of hereditary prostate cancer. J Urol. 1995; 153: 987-92.

22. Ray ME, Dunn RL, Cooney KA, Sandler HM: Family history of prostate cancer and relapse after definitive external beam radiation therapy. Int $\mathrm{J}$ Radiat Oncol Biol Phys. 2003; 57: 371-6.

23. Narod SA, Dupont A, Cusan L, Diamond P, Gomez JL, Suburu R, et al.: The impact of family history on early detection of prostate cancer. Nat Med. 1995; 1 : 99-101.

24. Amling CL, Riffenburgh RH, Sun L, Moul JW, Lance RS, Kusuda L, et al.: Soderdahl DW, Donahue TF, Foley JP, Chung AK, McLeod DG. Pathologic variables and recurrence rates as related to obesity and race in men with prostate cancer undergoing radical prostatectomy. J Clin Oncol. 2004; 22: 439-45.

25. Rohrmann S, Roberts WW, Walsh PC, Platz EA: Family history of prostate cancer and obesity in relation to high-grade disease and extraprostatic extension in young men with prostate cancer. Prostate. 2003; 55: 140-6.
Accepted after revision: March 17, 2010

\section{Correspondence address:}

Dr. Wade J. Sexton

Genitourinary Oncology Program

Moffitt Cancer Center

12902 Magnolia Drive

Tampa, Florida, 33612-9416, USA

Fax: + $1813745-8494$

E-mail: wade.sexton@Moffitt.org 


\section{EDITORIAL COMMENT}

This study revealed no significant differences between patients with familial histories compared with the patients without familial histories of prostate cancer in relation their age, preoperative PSA, Gleason score, pathological stage, and surgical status of the margin. However, important data that could be answered is related to the disease-specific survival and biochemical disease-free survival. Otherwise, patients with familial PC had a larger volume of cancer per gland compared with the sporadic prostate cancer group $-3.3 \mathrm{~cm}^{3}$ vs. $2.4 \mathrm{~cm}^{3}$. This tumoral volume data justifies more attention for men with a familial history of prostate cancer, since the larger the tumoral volume, the larger the chances of biochemical recurrence. In cases of smaller tumoral volume $(2.6 \mathrm{cc})$ normally the PSA is lower than 4.

\section{REFERENCE}

1. Zhu H, Roehl KA, Antenor JA, Catalona WJ: Biopsy of men with PSA level of 2.6 to $4.0 \mathrm{ng} / \mathrm{mL}$ associated with favorable pathologic features and PSA progression rate: a preliminary analysis. Urology. 2005; 66: 547-51.

Dr. Marcos F. Dall'Oglio University of Sao Paulo, USP Sao Paulo, Brazil E-mail: marcosdallogliouro@terra.com.br

\section{REPLY BY THE AUTHORS}

We agree with the editorial comments by Dr. Dall'Oglio that it would be interesting to analyze any differences in the survival characteristics (biochemical-free survival and disease specific survival) of patients with sporadic prostate cancer compared to patients with a family history of prostate cancer. As discussed in the manuscript however, there is no convincing evidence to date that a positive family history impacts survival in those who have received therapy for clinically localized prostate cancer. Fur- thermore, we found no difference in tumor volume $(p=0.27)$ in patients with a positive family history of prostate cancer $(1.72 \mathrm{~cm} 3)$ vs. patients with sporadic prostate cancer $(1.64 \mathrm{~cm} 3)$ as demonstrated in Table 1. Bastacky and colleagues (reference \#21 in the manuscript) found a non-statistically significant difference in the tumor volume of patients with familial prostate cancer compared to patients with sporadic prostate cancer $(3.3 \mathrm{~cm} 3$ vs. $2.4 \mathrm{~cm} 3)$.

The Authors 